\title{
Length Parameter for Scaling Abutment Scour Depth
}

\author{
Puer $\mathrm{Xu}{ }^{1,2}$, Niansheng Cheng ${ }^{2, *}$ and Maoxing Wei ${ }^{2}(\mathbb{D}$ \\ 1 State Key Laboratory of Water Resources and Hydropower Engineering Science, Wuhan University, \\ Wuhan 430072, China; pexu@zju.edu.cn \\ 2 Ocean College, Zhejiang University, Zhoushan 316021, China; mxwei@zju.edu.cn \\ * Correspondence: nscheng@zju.edu.cn
}

Received: 6 October 2020; Accepted: 7 December 2020; Published: 14 December 2020

\begin{abstract}
Flow constriction caused by bridge abutment increases bed shear stress and thus enhances local scour. For scaling the maximum scour depth at the abutment, either abutment length or flow depth has been empirically used in previous studies. By performing a step-by-step analysis, this study proposes a new length scale, which is able to represent combined effects of abutment length, approach flow depth and channel width. Physically, the new length scale describes the maximum possible dimension of the associated vortex system (or large-scale turbulence). Six series of data compiled from the published literature were used in the analysis. The results indicate that the new length scale helps improve the agreement of predictions with the experimental data.
\end{abstract}

Keywords: abutment scour; length scale; constriction effect; hydraulic radius; maximum scour depth

\section{Introduction}

Local scour at bridge abutments is the result of the erosion action of flowing water that removes bed material in rivers or coasts. Excessive scour can result in bridge failures, which costs millions of dollars each year to replace and restore bridges and relevant transportation facilities, and even loss of life [1]. Physically, due to the construction of the abutment, the otherwise uniform flow in the channel is subjected to significant blockage and constriction effects, resulting in a complex three-dimensional vortex system, which is sketched in Figure 1.

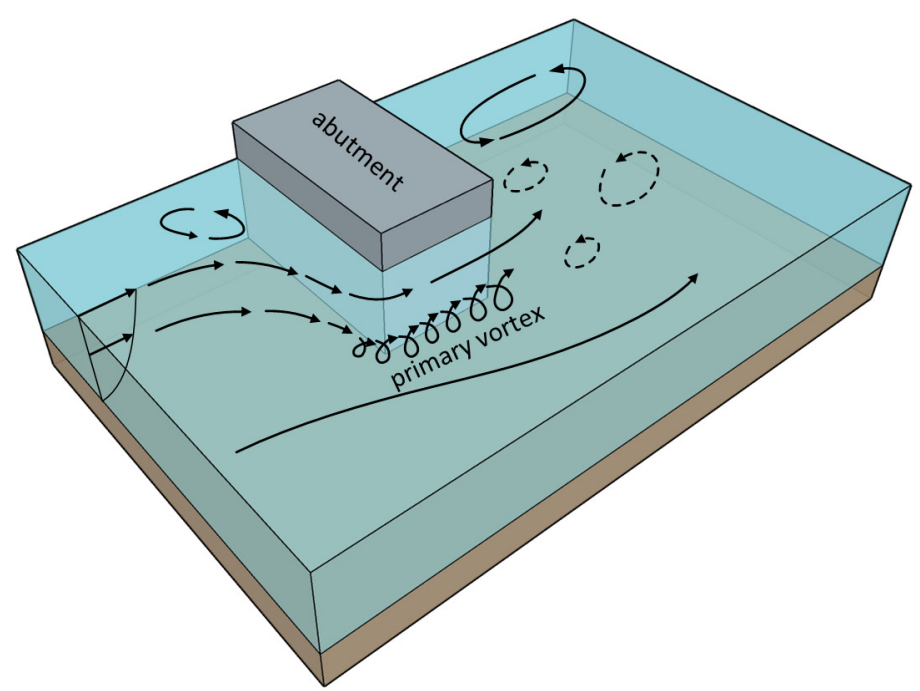

Figure 1. Schematic of flow structures around an abutment. 
Abutment scour has been studied for the last few decades in order to predict the maximum scour depth for design proposes [2]. Several kinds of length scale $L$ have been proposed in the literature to scale the maximum scour depth at abutments. For example, Lim [3] used the abutment length $b$ to scale the maximum scour depth, i.e., $L=b$, while Kandasamy and Melville [4] proposed the length scale as the flow depth $h$ or the abutment length $b$ multiplied by a coefficient, i.e., $L=K_{s} h$ or $L=K_{s} b$, where $K_{s}$ is a shape factor depending on $h / b$. Melville [5] recommended $L=h$ for long abutments $(b / h>25), L=b$ for short abutments $(b / h<1)$, and $L=(b h)^{0.5}$ for intermediate abutments $(1<b / h<25)$. All these choices were basically proposed on empirical grounds. In addition, with these diverse length scales, different empirical equations yield inconsistent predictions of scour depth. Thus far, it is still not clear how differently each of the pertinent parameters, such as approach flow depth, abutment length and channel width, affects the maximum scour depth at bridge abutments and what length scale should be used to better scale the maximum scour depth.

Unlike pier scour, which is mainly induced by the horseshoe vortex system, abutment scour is additionally affected by flow constriction that leads to an increase in the local flow velocity and bed shear stress. However, the constriction effect was often overlooked in the previous studies, e.g., Melville [6], Kothyari and Raju [7], Oliveto and Hager [8] and Coleman, et al. [9]. In comparison, only a few researchers, e.g., Garde, et al. [10] and Gill [11], considered that the local scour could be mostly affected by the constriction ratio, which was defined as the ratio of the transverse abutment length $b$ to the channel width $B$. More recently, Sturm, et al. [12] and Hong, et al. [13] highlighted the dominance of constriction effect, especially for long abutments. Given the simple configuration as sketched in Figure 2, in terms of length scales, the scour depth would be generally subjected to three parameters, i.e., the abutment length $b$, the channel width $B$ and the approach flow depth $h$. This is because in engineering applications and laboratory studies, $h$ could be in the order of $b$ and $B$. One may therefore surmise that the effects of $h$ and $B$ should be jointly taken into account along with $b$ in the scaling analysis of the maximum scour depth.

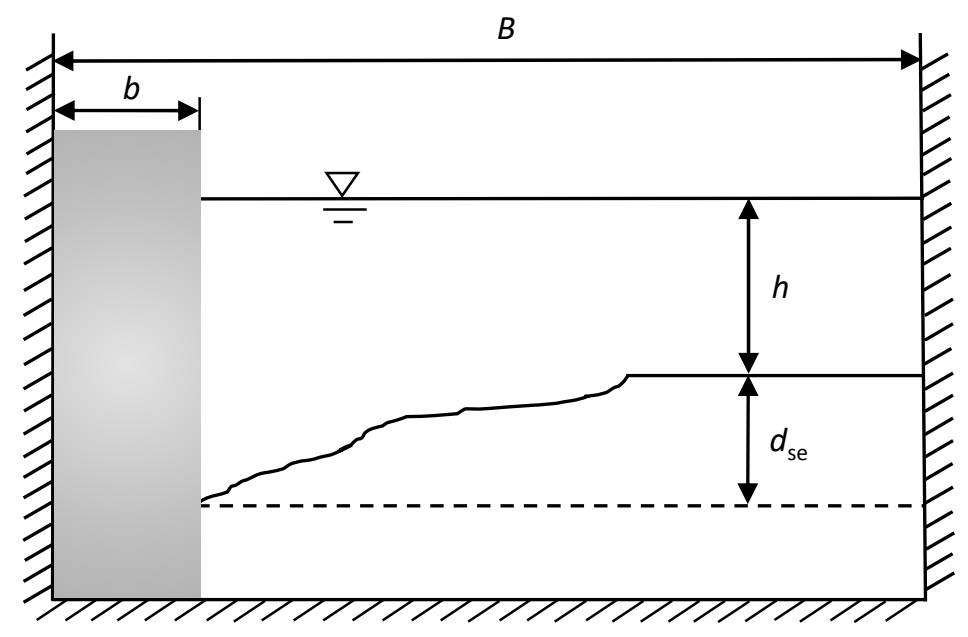

Figure 2. Schematic of abutment scour.

With the above consideration, this paper aims to formulate a unified length scale by incorporating all three parameters, i.e., flow depth, abutment length and channel width. In what follows, five possible length scale candidates are systematically considered in the context of five cases, which concern different sets of variables associated with the underlying mechanisms of abutment scour. Then, their goodness is tested and compared using experimental data from the published literature. Finally, a unified length scale is obtained. 


\section{Dimensional Analysis}

For the sake of simplicity, the following dimensional analysis begins with a simple case, where both the approach flow depth and the channel width are sufficiently large in comparison to the abutment length. In addition, to facilitate the analysis, it is assumed that (1) the approach flow is uniform, (2) the cross-section of the channel is rectangular, (3) the abutment is perpendicular to the main flow, (4) the sediment grains are uniformly sized, and (5) the viscous effect is negligible. Consequently, the equilibrium scour depth $d_{s e}$ depends on the following six parameters, i.e.,

$$
d_{s e}=f\left(b, U, d_{50}, \rho, \rho_{s}, g\right)
$$

where $b$ is the abutment length measured in the direction transverse to the flow, $U$ is the bulk velocity of the approach flow, $d_{50}$ is the median sediment grain diameter, $\rho$ is the fluid density, $\rho_{s}$ is the grain density, and $g$ is the gravitational acceleration. By noting that the reduced gravitational effect for submerged sediment grains can be described using $\Delta g=\left(\rho_{s} / \rho-1\right) g$ with $\Delta$ denoting $\rho_{s} / \rho-1$, Equation (1) can be reduced to

$$
d_{s e}=f\left(b, U, d_{50}, \Delta g\right)
$$

By performing the dimensional analysis and taking $d_{50}$ and $\Delta g$ as the repeating variables, Equation (2) can be rewritten in the dimensionless form as

$$
\frac{d_{s e}}{d_{50}}=f\left(F_{d}, \frac{b}{d_{50}}\right)
$$

where $F_{d}$ is the densimetric Froude number defined as

$$
F_{d}=\frac{U}{\sqrt{\Delta g d_{50}}}
$$

By noting that when ignoring the viscous effect, the settling velocity of a sediment particle is proportional to $\sqrt{\Delta g d_{50}}$. Therefore, $F_{d}$ quantifies the relative intensity of the approach flow in comparison to the gravitational effect of sediment particles. Equation (3) can be also rewritten as

$$
\frac{d_{s e}}{b}=f\left(F_{d}, \frac{d_{50}}{b}\right)
$$

Furthermore, assuming that $d_{50}$ is much smaller than $b$ so that the effect of $d_{50} / b$ is insignificant, one obtains

$$
\frac{d_{s e}}{b}=f\left(F_{d}\right)
$$

\section{Possible Length Scales}

In the preceding section, the abutment length $b$ is used as the length scale by assuming that both $h$ and $B$ are much larger than $b$. However, in practice, both the approach flow depth $h$ and the channel width $B$ could be in the order of the abutment length $b$ (i.e., $h \sim B \sim b$ ), and, therefore, they should also be considered for scaling the scour depth. To simplify the analysis, five cases are purposely devised and investigated.

Case $1(b<<h ; b<<B)$. This is the same as the case discussed in the foregoing dimension analysis. It represents the simplest scenario, for which the abutment length is much smaller than both $h$ and $B$ so that both effects of $h$ and $B$ can be ignored. Therefore, the length scale is simply represented by $b$, i.e.,

$$
L_{1}=b
$$


Case $2(h<<b ; h<<B)$. It is assumed that the flow is extremely shallow in comparison to both $b$ and $B$ so that the maximum scour depth would be dominantly affected by $h$ rather than either $b$ or $B$. For this case, the length scale should be replaced with $h$, i.e.,

$$
L_{2}=h
$$

Case $3(\boldsymbol{b} \sim \boldsymbol{h} ; \boldsymbol{b}<<\boldsymbol{B} ; \boldsymbol{h}<<\boldsymbol{B})$. The preceding two cases concern either $b$ or $h$ alone as the exclusively dominating parameter. When these two variables are of the same order, it is necessary to take both of them into account. It is noted that a similar scenario is ubiquitous in different types of local scour.

Recently, when studying pier scour, Cheng and Wei [14] proposed a length scale referred to as pier hydraulic radius $R_{p}$, which is defined as

$$
\frac{1}{R_{p}}=\frac{1}{0.5 d}+\frac{1}{h}
$$

where $d$ is the pier width. Cheng and Wei [14] reported that $R_{p}$ effectively incorporates the effects of both flow depth and pier width and physically represents the dimension of the horseshoe vortex formed in front of the pier. Their analysis showed that $R_{p}$ serves as a favorable length scale in scaling the pier scour depth. Melville [6] highlighted that the flow around an abutment is analogous to that around one half of a pier. As an approximation, an abutment could be considered as one half of a bridge pier. This implies that a length parameter similar to the pier hydraulic radius would be applicable for the abutment scour. Therefore, the length scale for Case 3 can be defined in the following form similar to Equation (9).

$$
\frac{1}{L_{3}}=\frac{1}{b}+\frac{1}{h}
$$

Equation (10) mathematically subsumes Case 1 and Case 2 since $L_{3} \sim b$ when $b<<h$ and $L_{3} \sim h$ when $h<<b$. Similar to the pier hydraulic radius, Equation (10) is expected to describe the dominating vortex size around an abutment.

Case $4(b \sim h \sim B)$. In this case, the channel width $B$ is assumed to be in the order of $b$ and $h$, meaning that the $B$-effect also needs to be included. To this end, one may resort to the conventional hydraulic radius $R_{h}$, which characterizes the dimension of the flow passing through a cross-section of an open channel. Being defined as the ratio of the area of cross-section to its wetted perimeter,

$$
R_{h}=\frac{B h}{B+2 h} \text { or } \frac{1}{R_{h}}=\frac{1}{h}+\frac{2}{B}
$$

For a wide channel $(B>>h), R_{h} \approx h$, and if $B$ is comparable to $h, R_{h}$ serves as a corrected flow depth. Given that $R_{h}$ physically represents an effective flow depth that inherently incorporates the $B$-effect, it is tempting to replace $h$ with $R_{h}$ in Equation (10). Consequently, the length scale for Case 4 is given by

$$
\frac{1}{L_{4}}=\frac{1}{b}+\frac{1}{R_{h}}=\frac{1}{b}+\frac{1}{h}+\frac{2}{B}
$$

Case $5(\boldsymbol{b} \sim \boldsymbol{h} \sim \boldsymbol{B}-\boldsymbol{b})$. Furthermore, it is noted that the abutment scour may also be subjected to the constricted channel, of which the width reduces to $B-b$. For this case, $B-b$ may be a better parameter to consider the constriction effect, and, therefore, the channel width $B$ in Equation (12) could be replaced with $B-b$, which yields

$$
\frac{1}{L_{5}}=\frac{1}{b}+\frac{1}{h}+\frac{2}{B-b}
$$

The above step-by-step analysis presents five different length scales (see Equations (7)-(13)), as summarized in Table 1 . Noting that when $b<<h, b<<B$ or $h<<b, h<<B, L_{5}$ asymptotes to $L_{1}$ and $L_{2}$, respectively, one may conjecture that $L_{5}$ could be used as a generalized length scale. 
Table 1. Summary of five length scale candidates.

\begin{tabular}{llc}
\hline Case & Constraint Condition & Length Scale \\
\hline 1 & $b<<h ; b<<B$ & $L_{1}=b$ \\
2 & $h<<b ; h<<B$ & $L_{2}=h$ \\
3 & $b \sim h ; b<<B ; h<<B$ & $L_{3}=\left(\frac{1}{b}+\frac{1}{h}\right)^{-1}$ \\
4 & $b \sim h \sim B$ & $L_{4}=\left(\frac{1}{b}+\frac{1}{h}+\frac{2}{B}\right)^{-1}$ \\
5 & $b \sim h \sim B-b$ & $L_{5}=\left(\frac{1}{b}+\frac{1}{h}+\frac{2}{B-b}\right)^{-1}$ \\
\hline
\end{tabular}

\section{Comparisons}

To test the proposed five length scales, six series of data covering both uniform and nonuniform sediments are compiled from the published literature [3,15-19]. A summary of the data is given in Table 2. It should be stated that all the data were collected only for the case of vertical wall abutment (as sketched in Figure 1).

By noting that the abutment constriction may significantly increase the average flow velocity, $U$ is corrected as $U B /(B-b)$. Consequently, $F_{d}$ in Equation (4) can be rewritten as

$$
F_{\mathrm{d} 1}=\frac{U}{\sqrt{\Delta g d_{50}}} \frac{B}{B-b}
$$

Considering the sediment gradation effect, Tan, et al. [20] suggested that $d_{84}\left(=\sigma_{g} d_{50}\right)$ is a better representative grain diameter than $d_{50}$ in reflecting the bed roughness during the scouring process. $F_{d 1}$ is therefore rewritten as

$$
F_{d 2}=\frac{U}{\sqrt{\Delta g \sigma_{g} d_{50}}} \frac{B}{B-b}
$$

It should be stated that the above modification associated with the densimetric Froude number and that related to the length scale (from L4 to L5) follow two different rationales, although both of them involve a factor of $B-b$. The former is a correction of local flow intensity, while the latter is a confinement of the geometrical dimension of the possible large-scale vortex that forms in the considered water body.

The dimensionless experimental ranges in terms of $d_{s e} / L_{i}(i=1-5)$ and $F_{d 2}$ are summarized in Table 3. 
Table 2. Compilation of experimental data.

\begin{tabular}{|c|c|c|c|c|c|c|c|c|c|c|c|}
\hline Author & Run & $\begin{array}{l}\text { Flow } \\
\text { Depth, } h \\
\text { (cm) }\end{array}$ & $\begin{array}{c}\text { Transverse } \\
\text { Abutment } \\
\text { Length, } b \\
\text { (cm) }\end{array}$ & $\begin{array}{l}\text { Channel } \\
\text { Width, B } \\
\text { (cm) }\end{array}$ & $\begin{array}{l}\text { Sediment Grain } \\
\text { Diameter, } d_{50} \\
\text { (cm) }\end{array}$ & $\begin{array}{c}\text { Geometric } \\
\text { Standard } \\
\text { Deviation, } \\
\sigma_{g}\end{array}$ & $\begin{array}{l}\text { Average Flow } \\
\text { Velocity, } U \\
(\mathrm{~m} / \mathrm{s})\end{array}$ & $\begin{array}{l}\text { Equilibrium } \\
\text { Scour Depth, } d_{s e} \\
(\mathrm{~cm})\end{array}$ & $b / B$ & $b / h$ & $b / d_{50}$ \\
\hline $\begin{array}{l}\text { Rajaratnam and } \\
\text { Nwachukwu [15] }\end{array}$ & $1-6$ & $10.7-15.4$ & 15.2 & 91 & 0.14 & $1.3^{*}$ & $0.204-0.320$ & $6.3-18.3$ & 0.17 & $0.99-1.42$ & 109 \\
\hline $\operatorname{Lim}[3]$ & S1-S11 & $10-15$ & $5-15$ & 60 & 0.094 & 1.25 & $0.181-0.325$ & $3.6-25.0$ & $0.08-0.25$ & $0.33-1.00$ & $53-160$ \\
\hline $\begin{array}{c}\text { Cardoso, Santos and } \\
\text { Roca [16] }\end{array}$ & $\mathrm{U} 1-\mathrm{U} 18$ & $6.9-7.1$ & $18-50$ & 145 & 0.063 & 1.68 & $0.141-0.277$ & $2.1-30.8$ & $0.12-0.34$ & $2.54-7.25$ & $286-794$ \\
\hline Molinas [17] & $\begin{array}{l}\text { Set A } \\
\text { Set B } \\
\text { Set C } \\
\text { Set G }\end{array}$ & $\begin{array}{c}2.8-15.2 \\
2.6-15.2 \\
3.3-9.3 \\
7.3-9.8\end{array}$ & $\begin{array}{l}2.5-10.2 \\
5.1-10.2 \\
5.1-10.2 \\
5.1-10.2\end{array}$ & $\begin{array}{l}61 \\
61 \\
61 \\
61\end{array}$ & $\begin{array}{l}0.18 \\
0.18 \\
0.18 \\
0.18\end{array}$ & $\begin{array}{c}2.07 \\
1.17 \\
3.91 \\
1.3\end{array}$ & $\begin{array}{c}0.19-0.42 \\
0.206-0.463 \\
0.21-0.443 \\
0.135-0.304\end{array}$ & $\begin{array}{c}0.5-8.3 \\
2-14.94 \\
0.3-4.5 \\
0.1-11.9\end{array}$ & $\begin{array}{l}0.04-0.17 \\
0.08-0.17 \\
0.08-0.17 \\
0.08-0.17\end{array}$ & $\begin{array}{l}0.24-2.62 \\
0.43-3.64 \\
0.61-2.68 \\
0.61-1.12\end{array}$ & $\begin{array}{c}14-57 \\
28-57 \\
28-57 \\
65-131\end{array}$ \\
\hline $\begin{array}{l}\text { Fael, Simarro-Grande, } \\
\text { Martín-Vide and } \\
\text { Cardoso [18] }\end{array}$ & S.1-S.31 & $5.1-7.2$ & $64-186$ & 400 & 0.128 & 1.46 & $0.123-0.385$ & $6.7-42.6$ & $0.16-0.47$ & $8.89-36.47$ & $617-1453$ \\
\hline $\begin{array}{l}\text { Ballio, Teruzzi and } \\
\text { Radice [19] }\end{array}$ & A10-D51 & $9.0-18.3$ & $5.0-20.5$ & 15-193 & $0.19-0.5$ & 1.3 & $0.45-0.72$ & $13.4-47$ & $0.1-0.51$ & $0.54-2.07$ & 10-108 \\
\hline
\end{tabular}


Table 3. Summary of dimensionless experimental ranges.

\begin{tabular}{|c|c|c|c|c|c|c|}
\hline Author & $d_{s e} / L_{1}$ & $d_{s e} / L_{2}$ & $d_{s e} / L_{3}$ & $d_{s e} / L_{4}$ & $d_{s e} / L_{5}$ & $F_{d 2}$ \\
\hline $\begin{array}{l}\text { Rajaratnam and } \\
\text { Nwachukwu [15] }\end{array}$ & $0.41-1.20$ & $0.54-1.71$ & $0.95-2.91$ & $1.09-3.31$ & $1.12-3.39$ & $1.43-2.24$ \\
\hline $\operatorname{Lim}[3]$ & $0.57-1.67$ & $0.24-1.67$ & $0.73-3.33$ & $0.92-4.17$ & $0.98-4.44$ & $1.75-3.14$ \\
\hline $\begin{array}{l}\text { Cardoso, Santos } \\
\text { and Roca [16] }\end{array}$ & $0.09-1.17$ & $0.30-4.34$ & $0.42-4.95$ & $0.45-5.38$ & $0.45-5.60$ & $1.49-3.23$ \\
\hline Molinas [17] & $0.01-2.30$ & $0.01-3.06$ & $0.21-4.50$ & $0.02-4.87$ & $0.03-4.93$ & $0.75-2.74$ \\
\hline $\begin{array}{c}\text { Fael, Simarro-Grande, } \\
\text { Martín-Vide } \\
\text { and Cardoso [18] }\end{array}$ & $0.04-0.46$ & $0.86-6.87$ & $0.90-7.10$ & $0.93-7.31$ & $0.95-7.50$ & $1.23-4.13$ \\
\hline $\begin{array}{l}\text { Ballio, Teruzzi } \\
\text { and Radice [19] }\end{array}$ & $1.82-3.42$ & $1.44-4.56$ & $4.12-6.86$ & $4.39-9.21$ & $4.40-11.68$ & $2.06-4.62$ \\
\hline
\end{tabular}

Figures 3-7 illustrate the dependency of $d_{s e} / L_{i}$ on $F_{d 2}$, where $L_{i}(i=1-5)$ represents the five length scale candidates as formulated in the preceding section. The value of the correlation coefficient $r$ between $d_{s e} / L_{i}$ and $F_{d 2}$ is also shown in the figures.

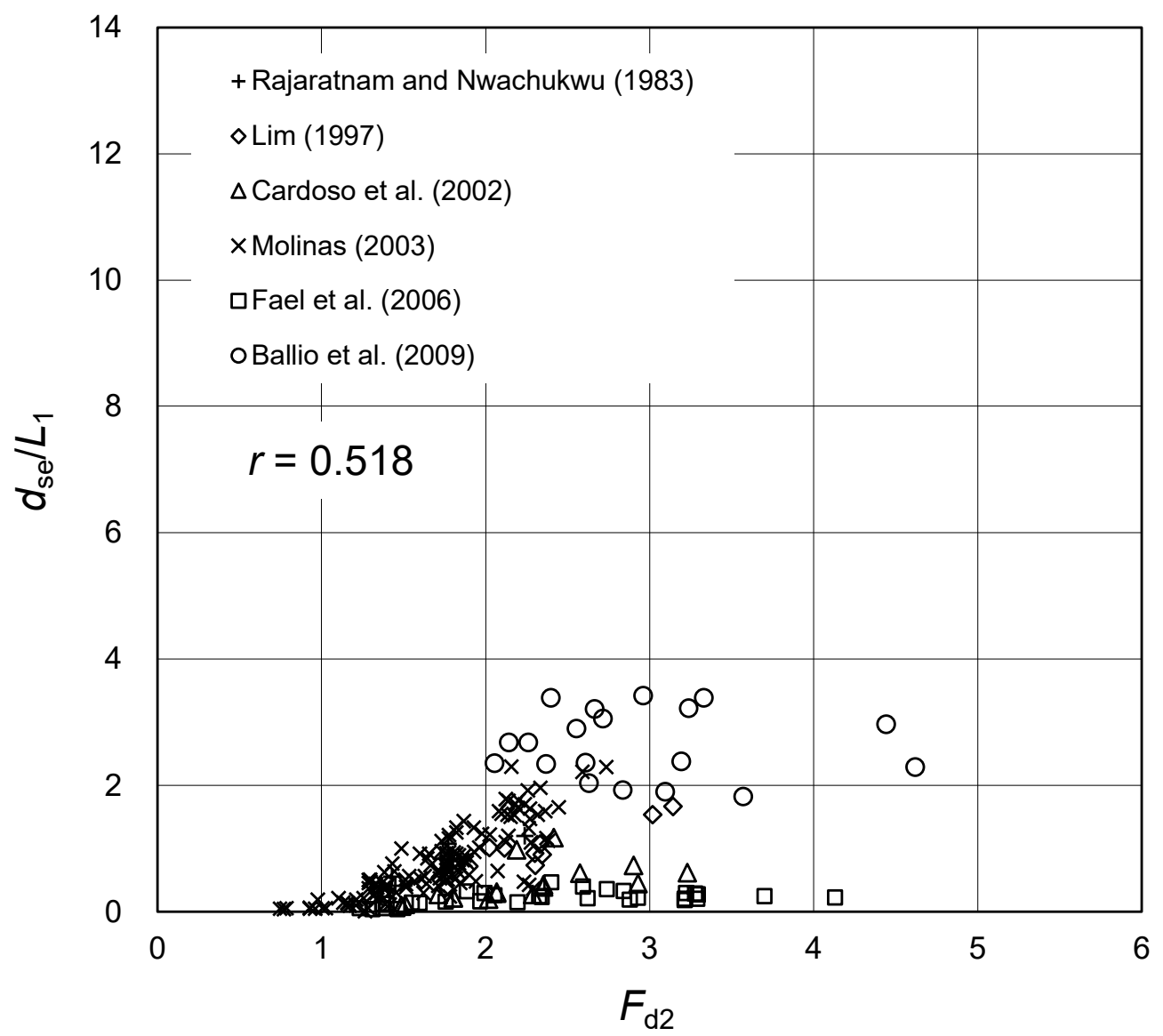

Figure 3. Plot of $d_{s e} / L_{1}$ against $F_{d 2}\left(L_{1}=b\right)$. 


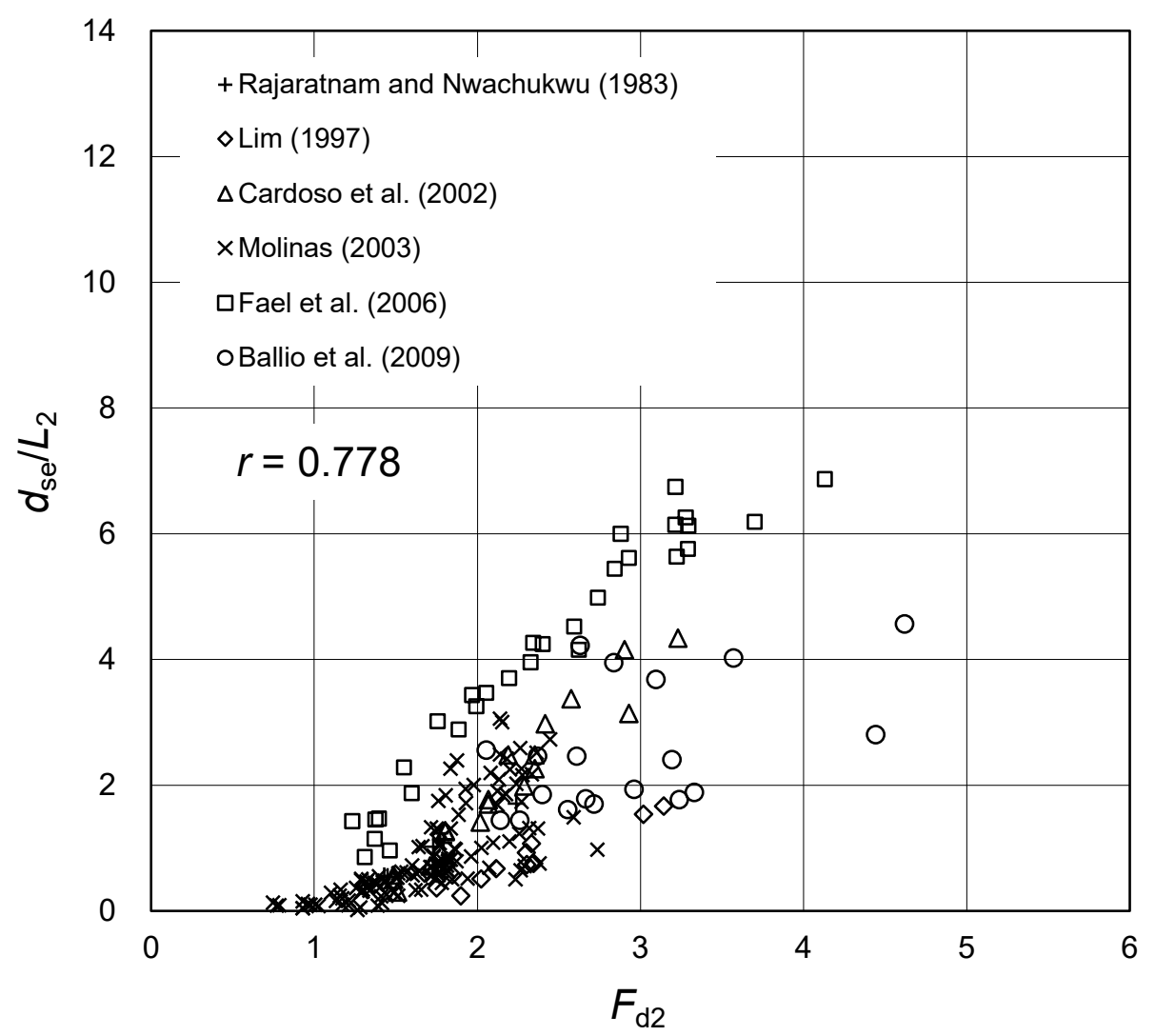

Figure 4. Plot of $d_{s e} / L_{2}$ against $F_{d 2}\left(L_{2}=h\right)$.

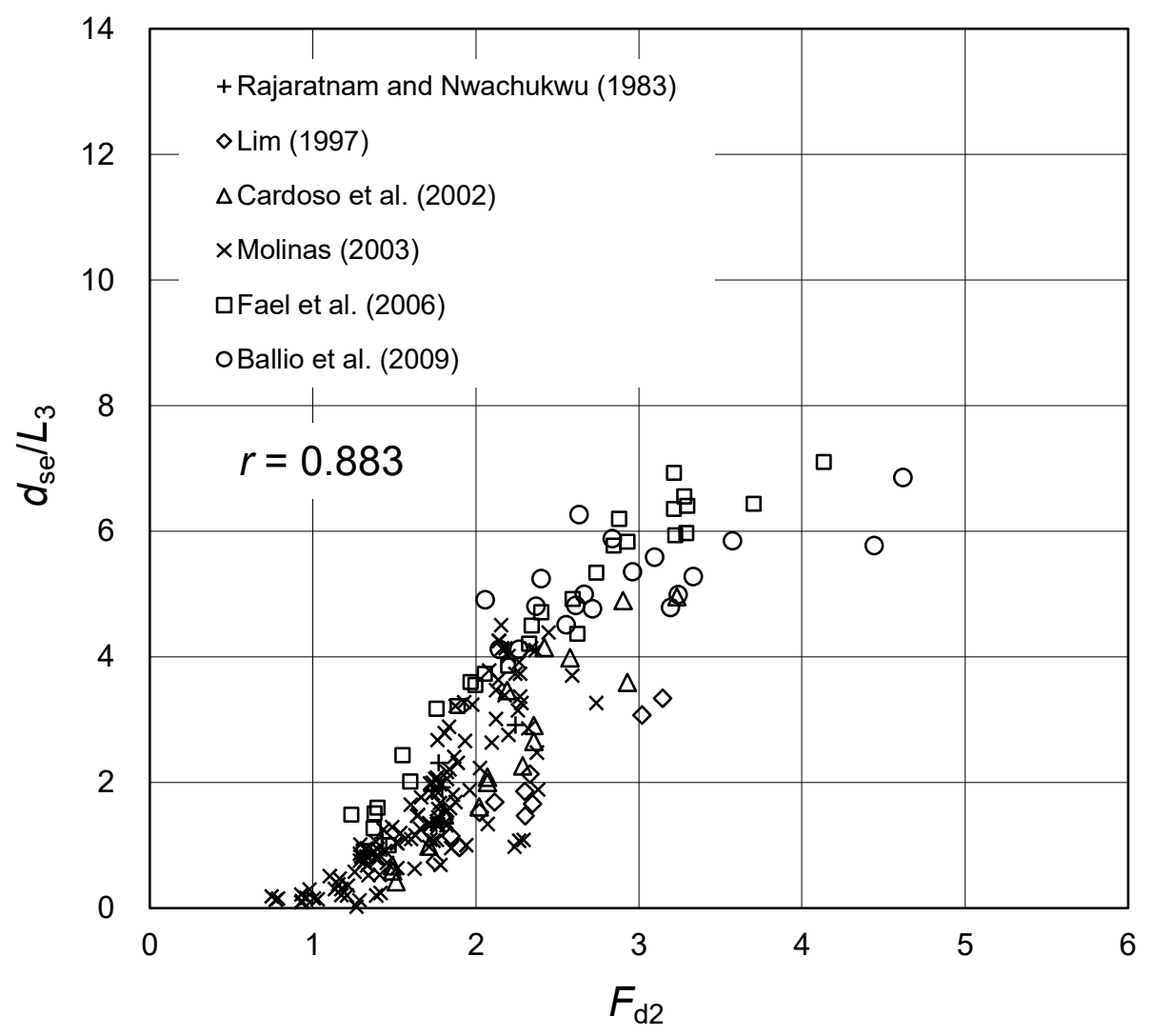

Figure 5. Plot of $d_{s e} / L_{3}$ against $F_{d 2}\left[L_{3}=\left(\frac{1}{b}+\frac{1}{h}\right)^{-1}\right]$. 


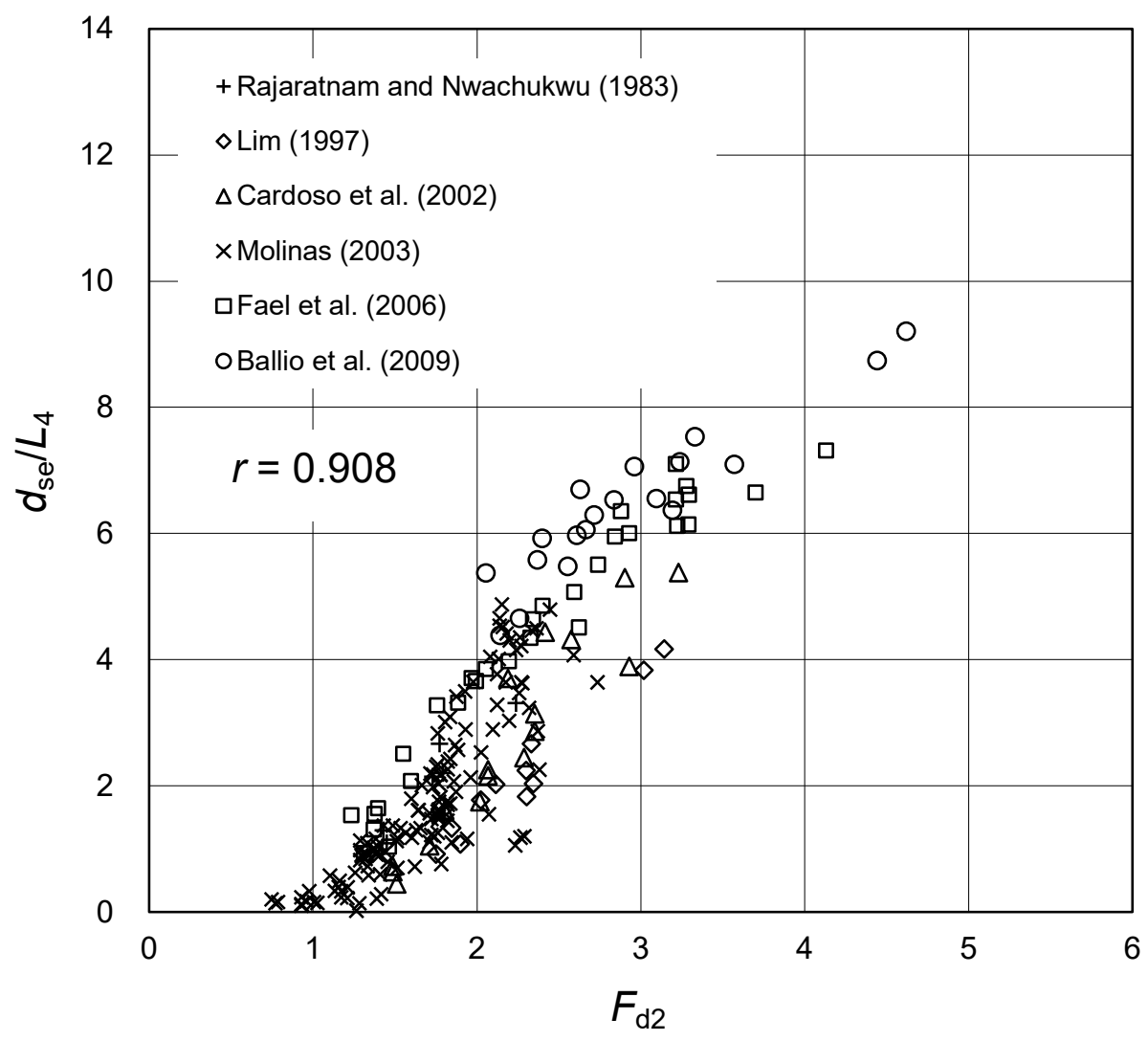

Figure 6. Plot of $d_{s e} / L_{4}$ against $F_{d 2}\left[L_{4}=\left(\frac{1}{b}+\frac{1}{h}+\frac{2}{B}\right)^{-1}\right]$.

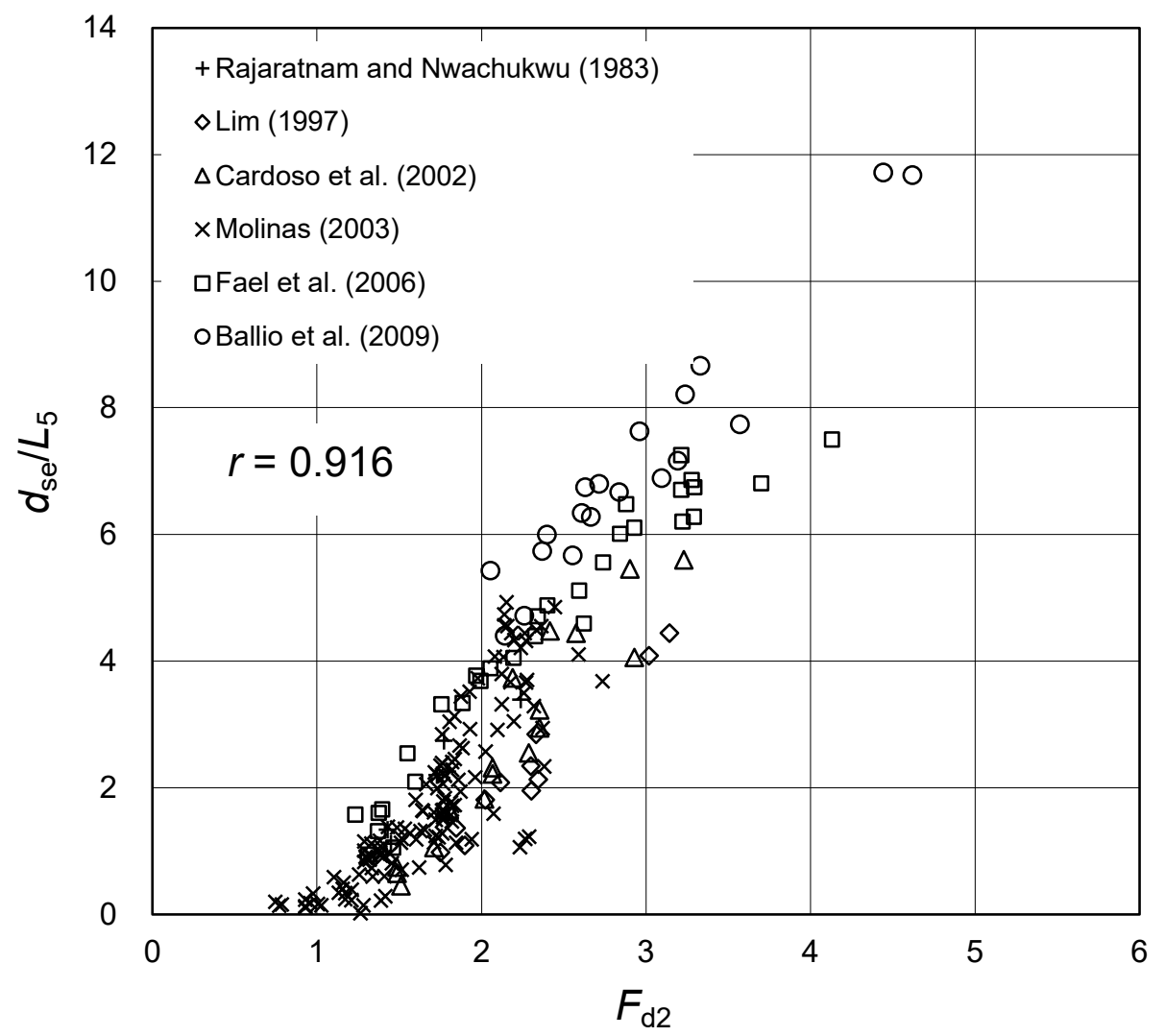

Figure 7. Plot of $d_{s e} / L_{5}$ against $F_{d 2}\left[L_{5}=\left(\frac{1}{b}+\frac{1}{h}+\frac{2}{B-b}\right)^{-1}\right]$. 
From Figures 3 and 4, it can be clearly observed that marked differences exist among the six series of experimental data, and each individual series does not show any meaningful trend. This implies that either $b$ or $h$ alone appears to be incapable of explaining all data series.

When taking both the abutment length and the approach flow depth into consideration, Figure 5 shows that the data points exhibit a better trend compared to the scattering data points in Figures 3 and 4. This is indicative of the fact that the combined length scale $L_{3}\left[=\left(\frac{1}{b}+\frac{1}{h}\right)^{-1}\right]$ possesses a better applicability than either $b$ or $h$. Notwithstanding, this is not the best case yet, as some of the data points still deviate from the averaged trend.

Figure 6 plotting $d_{s e} / L_{4}$ against $F_{d 2}$ shows a further improvement as the constriction effect is considered in $L_{4}$. This improvement confirms the necessity of including the $B$-effect when $b$ and $B$ are of the same order, for example, $0.1<b / B<0.5$ for most of the data used here (see Table 2). One may therefore conclude that $L_{4}\left[=\left(\frac{1}{b}+\frac{1}{R_{h}}\right)^{-1}\right]$ acts as a better length scale than $b, h$ and their combination when the constriction effect is significant.

Furthermore, Figure 7 shows that by replacing $B$ with $B-b$ and using $L_{5}$, the data points complied from the different independent studies generally follow a unified trend. The calculated correlation coefficients for Figures 3-7 also confirm that $L_{5}$ yields the best correlation among the five length scale candidates.

Given the gradual improvement with a series of modifications in the length scale, it can be concluded that $L_{5}\left[=\left(\frac{1}{b}+\frac{1}{h}+\frac{2}{B-b}\right)^{-1}\right]$, which considers the combined effects of abutment length, flow depth, and reduced channel width, serves as the best length scale for scaling the maximum scour depth at an abutment.

\section{Discussion}

The length scale $L_{5}\left[=\left(\frac{1}{b}+\frac{1}{h}+\frac{2}{B-b}\right)^{-1}\right]$ proposed in this study provides a reasonable quantification of the length scale of the three-dimensionality of the water body. Following the rationale given by Cheng and Wei [14], $L_{5}$ describes the maximum possible dimension of the vortex system (or the large-scale turbulence). On empirical grounds, many observations in the past have shown that the large-scale flow structure (i.e., the horseshoe vortex at piers or the primary vortex at abutments) is the leading cause for the scouring action [21-24]. In this view, the effectiveness of the proposed length scale in normalizing the scour depth may, to some extent, imply that the simple combination of abutment length, flow depth, and channel width can be regarded as a characteristic measure of the large-scale turbulence structure around an abutment. Further efforts in physically measuring or numerically simulating the flow structures around an abutment are therefore needed to confirm such inference. Moreover, although the newly proposed length scale is able to coordinate the extensive scattering data points to follow a unified trend, some dispersions among different datasets still persist. This is probably attributed to the fact that effects of some other pertinent parameters such as the abutment width (measured in the longitudinal direction), and sediment size [25] are still not explicitly covered. For example, one may deduce that for a given densimetric Froude number, a wider abutment would lead to a more marked constriction effect and therefore a larger scour depth. Consequently, it may be still premature to propose another empirical equation at this stage.

\section{Conclusions}

This study presents a step-by-step analysis in the formulation of a unified length scale for scaling the maximum scour depth at an abutment. The results show that the main governing parameters, abutment length, flow depth and channel width, can be combined, on physical grounds, to yield a unified length scale. By comparing the experimental data, it can be observed that the new length scale achieves a much better agreement than its commonly used predecessors. It must be stated that some other parameters, such as abutment width (in the streamwise direction), shape and alignment, and cross-sectional channel geometry, are not considered in this study. 
Author Contributions: Conceptualization, N.C.; data curation, P.X., N.C., M.W.; formal analysis, P.X., N.C., M.W.; supervision, N.C. and M.W.; writing-original draft, P.X.; writing-review and editing, P.X., N.C. and M.W. All authors have read and agreed to the published version of the manuscript.

Funding: This research was funded by the National Natural Science Foundation of China (Grant No. 51979242).

Acknowledgments: The data supporting the conclusions can be obtained in the references.

Conflicts of Interest: The authors declare no conflict of interest.

\section{Notation}

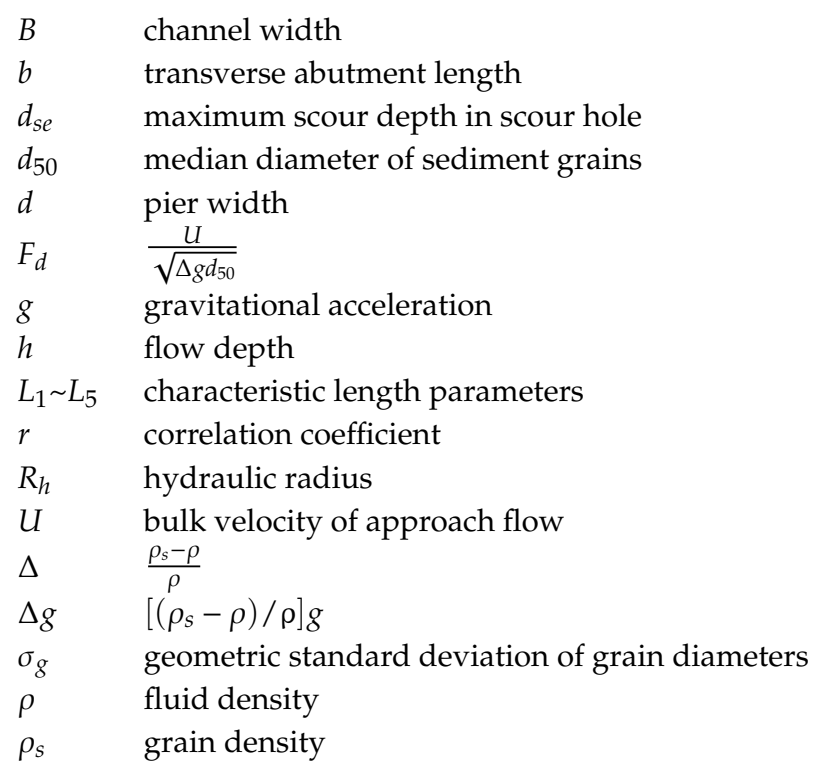

\section{References}

1. Richardson, E.V.; Lagasse, P.F.; Schall, J.D.; Ruff, J.F.; Brisbane, T.E.; Frick, D.M. Hydraulic, Erosion and Channel Stability Analysis of the Schoharie Creek Bridge failure, New York; Resources Consultants, Inc.: Fort Collins, CO, USA; Colorado State University: Fort Collins, CO, USA, 1987.

2. Ettema, R.; Nakato, T.; Muste, M. Estimation of Scour Depth at Bridge Abutments; Transportation Research Board: Washington, DC, USA, 2010.

3. Lim, S.-Y. Equilibrium clear-water scour around an abutment. J. Hydraul. Eng. 1997, 123, 237-243. [CrossRef]

4. Kandasamy, J.K.; Melville, B.W. Maximum local scour depth at bridge piers and abutments. J. Hydraul. Res. 1998, 36, 183-198. [CrossRef]

5. Melville, B.W. Local scour at bridge abutments. J. Hydraul. Eng. 1992, 118, 615-631. [CrossRef]

6. Melville, B.W. Pier and abutment scour: Integrated approach. J. Hydraul. Eng. 1997, 123, 125-136. [CrossRef]

7. Kothyari, U.; Raju, K. Scour around spur dikes and bridge abutments. J. Hydraul. Res. 2001, 39, 367-374. [CrossRef]

8. Oliveto, G.; Hager, W.H. Temporal evolution of clear-water pier and abutment scour. J. Hydraul. Eng. 2002, 128, 811-820. [CrossRef]

9. Coleman, S.E.; Lauchlan, C.S.; Melville, B.W. Clear-water scour development at bridge abutments. J. Hydraul. Res. 2003, 41, 521-531. [CrossRef]

10. Garde, R.J.; Subramanya, K.S.; Nambudripad, K.D. Study of scour around spur-dikes. J. Hydraul. Div. 1961, 87, 23-37.

11. Gill, M.A. Erosion of sand beds around spur dikes. J. Hydraul. Div. 1972, 98, 1587-1602.

12. Sturm, T.W.; Ettema, R.; Melville, B. Evaluation of bridge-scour research abutment and contraction scour processes and prediction. Washington, D.C. In National Cooperative Highway Research Program; Transportation Research Board of the National Academies: Washington, DC, USA, 2011.

13. Hong, S.H.; Sturm, T.W.; Stoesser, T. Clear water abutment scour in a compound channel for extreme hydrologic events. J. Hydraul. Eng. 2015, 141, 1-12. [CrossRef] 
14. Cheng, N.-S.; Wei, M. Scaling of scour depth at bridge pier based on characteristic dimension of large-scale vortex. Water 2019, 11, 2458. [CrossRef]

15. Rajaratnam, N.; Nwachukwu, B.A. Erosion near groin-like structures. J. Hydraul. Res. 1983, 21, $277-287$. [CrossRef]

16. Cardoso, A.H.; Santos, J.S.; Roca, M. Effects of flow intensity, obstacle alignmnet and cross-section geometry on scour at bridge abutments. Int. J. Sediment Res. 2002, 17, 339-340.

17. Molinas, A. Bridge Scour in Nonuniform Sediment Mixtures and in Cohesive Materials: Synthesis Report; No. FHWA-RD-03-083; Federal Highway Administration: McLean, VA, USA, 2003.

18. Fael, C.M.S.; Simarro-Grande, G.; Martín-Vide, J.-P.; Cardoso, A.H. Local scour at vertical-wall abutments under clear-water flow conditions. Water Resour. Res. 2006, 42. [CrossRef]

19. Ballio, F.; Teruzzi, A.; Radice, A. Constriction effects in clear-water scour at abutments. J. Hydraul. Eng. 2009, 135, 140. [CrossRef]

20. Tan, S.M.; Lim, S.Y.; Wei, M.X.; Cheng, N.S. Application of particle densimetric froude number for evaluating the maximum culvert scour depth. J. Irrig. Drain. Eng. 2020, 146, 04020020. [CrossRef]

21. Breusers, H.N.C.; Nicollet, G.; Shen, H.W. Local scour around cylindrical piers. J. Hydraul. Res. 1977, 15, 211-252. [CrossRef]

22. Simpson, R.L. Junction flows. Annu. Rev. Fluid Mech. 2001, 33, 415-443. [CrossRef]

23. Unger, J.; Hager, W.H. Down-flow and horseshoe vortex characteristics of sediment embedded bridge piers. Exp. Fluids 2007, 42,1-19. [CrossRef]

24. Zhao, M.; Cheng, L.; Zang, Z. Experimental and numerical investigation of local scour around a submerged vertical circular cylinder in steady currents. Coast. Eng. 2010, 57, 709-721. [CrossRef]

25. Lee, S.O.; Sturm, T.W. Effect of Sediment Size Scaling on Physical Modeling of Bridge Pier Scour. J. Hydraul. Eng. 2009, 135, 793-802. [CrossRef]

Publisher's Note: MDPI stays neutral with regard to jurisdictional claims in published maps and institutional affiliations.

(C) 2020 by the authors. Licensee MDPI, Basel, Switzerland. This article is an open access article distributed under the terms and conditions of the Creative Commons Attribution (CC BY) license (http://creativecommons.org/licenses/by/4.0/). 